\title{
Analysis of agroclimatic resources for Georgian viticulture
}

\author{
David Maghradze ${ }^{1}$, Gabriele Cola ${ }^{2 *}$, Luigi Mariani ${ }^{3}$ and Osvaldo Failla ${ }^{2}$ \\ ${ }^{1}$ National Wine Agency of Georgia, Tbilisi, Georgia \\ ${ }^{2}$ Department of Agricultural and Environmental Sciences - Production, Landscape, Agroenergy, Università degli Studi di Milano \\ ${ }^{3}$ Lombard Museum of History of Agriculture
}

\begin{abstract}
One of the results of the "Research Project for the Study of Georgian Grapes and Wine Culture" promoted by the National Wine Agency of the Republic of Georgia was the production of a bilingual handbook for modern viticulture. The first sections of the handbook were devoted to the agrometeorological analysis of environmental resources and limitations, comprising a general analysis of Georgian climate and agrometeorological features, followed by detailed regional cards. The agrometeorological analysis of Georgia was based on daily data collected by National and International networks for the period 1974-2013. Several agrometeorological indexes were calculated in order to define resources and limitations for viticulture for each viticultural region of Georgia, providing fundamental information for grape-growing and wine-making.
\end{abstract}

\section{Introduction}

Georgia is considered the cradle of World viticulture [1](McGovern et al., 2017), being the core of the first domestication of grapevine (Vitis vinifera L.) from its wild ancestor Vitis vinifera ssp. silvestris [2](Zohary and Hopf 2000). The great number of Georgian varieties (more than 500) [3], covering $95 \%$ of the vineyards, yield quality wines, highly rated by tasting panels over the world [4]. This genetic richness is an interesting source of biodiversity and a tool for the resilience of viticulture to face climate and environmental changes [5, 6].

In the current viticultural context, an update of the traditional viticultural models defined many decades ago is necessary to face the evolving demands of the global market, taking into account the current climatic pattern of Georgia. For this reason, the first step for the development of new viticultural models was the agrometeorological analysis of wine regions in Georgia, defining resources and limitations for grape growing.

\section{Materials and methods}

The agrometeorological analysis of Georgia is based on the collection of daily precipitation data and maximum and minimum temperature for the period 1974-2013, covering Georgia and neighbouring countries. Data from 273 weather stations were collected from the following sources:

1) Georgian National Environmental Agency Department of Hydrometeorology,
2) ECA\&D (the European Climate Assessment \& Dataset project),

3) US NOAA (Global Surface Summary Of the Day by).

Daily fields of temperature and precipitation (with a spatial resolution of 0.01666 degrees) were obtained by means of geostatistical algorithms (Inverse Square Distance with homogenization for elevation in the case of temperature, inverse square distance for precipitation) [7].

A change point analysis [8], was applied to the yearly mean temperature of the whole set of Georgian stations for the period 1974-2013 in order to detect possible break points in Georgian climate. As shown in figure 1, the analysis found 1994 as the beginning of a warmer phase for Georgian climate $\left(+1.4^{\circ} \mathrm{C}\right)$ while Western Europe faced an increase of about $1{ }^{\circ} \mathrm{C}$, with 1987 as the most likely year of change [9].
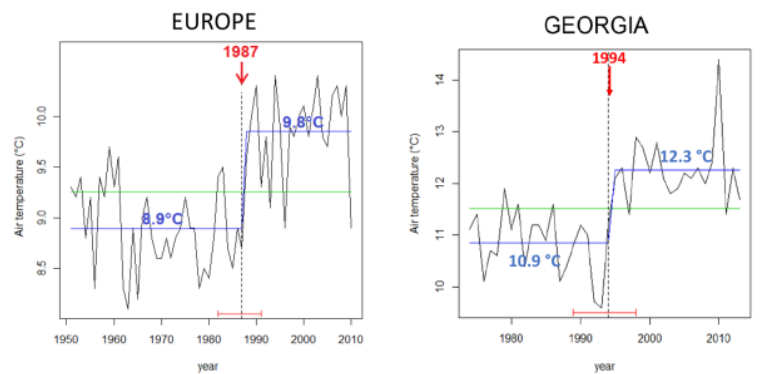

Fig. 1. Change point analysis of average yearly temperature performed for Western Europe and Georgia. 
The delay in the change of temperature between Georgia and Western Europe could be an effect of the progressive dilution of the Oceanic signal as it moves into the European continent. The abrupt change observed for Georgia could be directly related to the transition from a negative to a positive phase of the circulation index AMO - Atlantic Multidecadal Oscillation - that took place in 1994, a transition triggered by years of strong positive values of the circulation index NAO North Atlantic Oscillation [10] - that started in 1987.

Based on this evidence, the agrometeorological characterization of Georgia considered two periods:

1) 1994-2013 - adopted for the characterization of current climate, thermal indexes and phenology.

2) 1974-2013 - adopted for the computation of the extreme event indexes and for water balance elaborations, when larger time spans are needed in order to obtain robust results.

The agrometeorological characterization was performed at the national and regional level and comprises the following analysis:

1) Köeppen - Geiger classification - one of the most widely used systems for classifying the world climates, based on the annual and monthly averages of temperature and precipitation $[11,12]$. In Georgia the following types are present: ET, Dfa, Dfb, Dfc, Cfa, Cfb, $\mathrm{Cfc}$ and Bsk. The Köeppen - Geiger classification.

2) Bagnouls Gaussen Diagram - based on average monthly data of precipitation, mean temperature and absolute minimum temperature referred to the 19742013 period, this diagram provides information about drought conditions, water excess and risk of frost. Diagrams were performed for each grape growing region, distinguishing among different elevation belts (0250, 250-500, 500-750, 750-1000, 1000-1250 m).

3) Thermo-pluviometric features - maps of yearly precipitation, maximum and minimum yearly temperature (1994-2013)

4) Thermal Resources and Limitations - maps of Winkler index, beginning of vegetative season, day of beginning of flowering, day of Fruit Set, beginning of Vegetative Season (reffered to the 1994-2013 period), Summer Stress, Spring Frost, Winter Frost (referred to the 1974-2013 period).

Phenological information was obtained by means of a tailored phenological model developed for Georgian varieties [13].

The risk of summer stress was expressed as the percentage of the years of the reference period with at least 7 days with maximum temperature above the $35^{\circ} \mathrm{C}$ threshold, the risk of spring frost as the percentage of the years of the reference period with spring minimum temperature below the $-2^{\circ} \mathrm{C}$ threshold and the risk of winter frost as the percentage of the years of the reference period with winter minimum temperature below the $-15^{\circ} \mathrm{C}$ threshold.

5) Water Resources and Limitations: by means of maps of Reference Crop Evapotranspiration ET0, Maximum Evapotranspiration ETM, Real Evapotranspiration ETR, Water Excess and Water Shortage (for the period 19742013). ET0 was calculated by means of the Hargreaves and Samani method [14], ETM by applying dynamic FAO crop coefficient Kc [14].

ETR, Water Excess and Water Shortage were calculated by means of a daily water balance based on a single layer soil reservoir. Two AWC were considered: 100 $\mathrm{mm}$ to describe soils with low water capacity and 200 $\mathrm{mm}$ to represent soils with high water capacity.

\section{Results and discussion}

The final results presented in the handbook are divided into a general section and twelve regional cards. In the general section, the climate of Georgia is discussed, taking into account its circulation drivers and the previously discussed change point analysis, detecting the climate change of 1994. Finally, national maps of all the agrometeorological indexes are included.

After the general section, regional cards provide a more detailed description of the region's climate together with the maps of the agrometeorological indexes and three tables, containing useful information for vineyard management.

Examples of regional cards contents are presented in figure 2, 3 and 4 with reference to Imereti region.

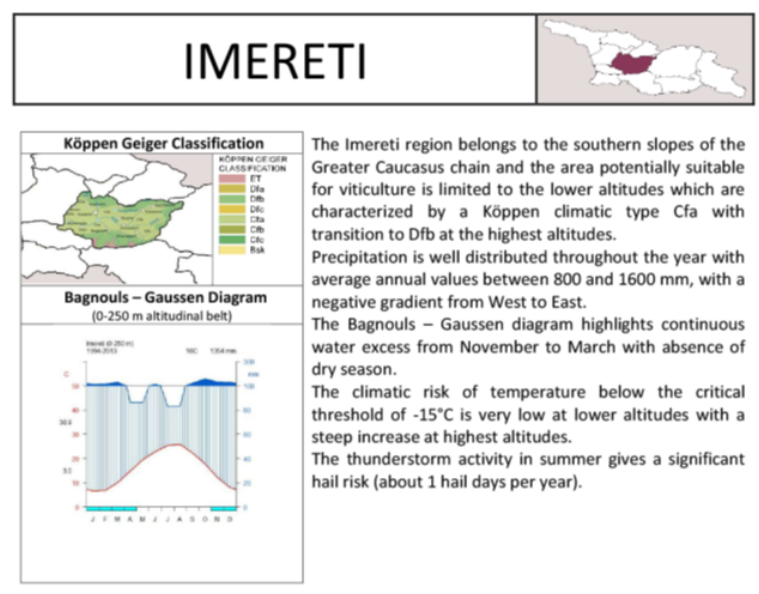

Fig. 2. Imereti region card, climate.

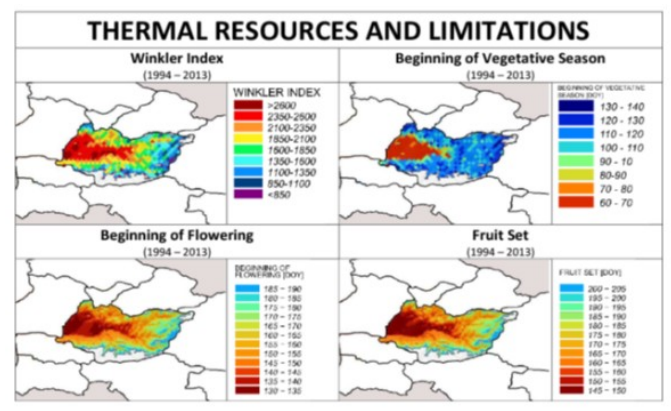

Fig. 3. Imereti region card, thermal resources and limitations. 


\begin{tabular}{|c|c|c|c|c|c|c|c|c|}
\hline Elovation belt $(m)$ & \multicolumn{2}{|c|}{ \% of the total surface } & $\begin{array}{c}\text { Phonological } \\
\text { timing }\end{array}$ & $\begin{array}{l}\text { Winkler } \\
\text { Class }\end{array}$ & \multicolumn{2}{|c|}{ Risk of winter frost } & \multicolumn{2}{|c|}{ Risk of spring frost } \\
\hline $0-250$ & \multicolumn{2}{|l|}{30.4} & earty & v & \multicolumn{2}{|c|}{ very low } & \multicolumn{2}{|c|}{ very low - very high } \\
\hline $250-500$ & \multicolumn{2}{|l|}{18.3} & early & IV & \multicolumn{2}{|c|}{ low } & \multicolumn{2}{|c|}{ very low - very high } \\
\hline $500-750$ & \multicolumn{2}{|l|}{25.4} & medium & III & \multicolumn{2}{|c|}{ low } & \multicolumn{2}{|c|}{ very low - very high } \\
\hline 750-1000 & \multicolumn{2}{|l|}{15.0} & late & 1 & \multicolumn{2}{|l|}{ low } & \multicolumn{2}{|c|}{ very low - very high } \\
\hline $1000-1250$ & \multicolumn{2}{|l|}{10.9} & late & 1 & \multicolumn{2}{|c|}{ low - very high } & \multicolumn{2}{|c|}{ very low - very high } \\
\hline Elevation bolt $(\mathrm{m})$ & \multicolumn{2}{|c|}{$\begin{array}{l}\text { Risk of summer light- } \\
\text { thermal stress }\end{array}$} & \multicolumn{2}{|c|}{$\begin{array}{l}\text { Risk of summer } \\
\text { water stress }\end{array}$} & \multicolumn{2}{|c|}{$\begin{array}{c}\text { Risk of spring water } \\
\text { excoss }\end{array}$} & \multicolumn{2}{|c|}{$\begin{array}{l}\text { Risk of water oxcess } \\
\text { during ripening }\end{array}$} \\
\hline $0-250$ & \multicolumn{2}{|c|}{ very high } & \multicolumn{2}{|r|}{ very low } & \multicolumn{2}{|c|}{ low - medium } & & high \\
\hline $250-500$ & \multicolumn{2}{|c|}{ high - very high } & \multicolumn{2}{|r|}{ very low } & \multicolumn{2}{|c|}{ low - medium } & & high \\
\hline $500-750$ & \multicolumn{2}{|c|}{ very low - very high } & & very low & low-mediun & & & high \\
\hline $750-1000$ & very low - very & high & & y low - medium & low-mediun & & & high \\
\hline 1000-1250 & very low & & & y low - medium & low - mediun & & & high \\
\hline Elovation bolt ( $m$ ) & $\begin{array}{l}\text { Targot yiold } \\
\text { (tha) }\end{array}$ & Vine & density & $\begin{array}{c}\text { Canopy } \\
\text { hoight } \\
\text { vs. } \\
\text { row distance }\end{array}$ & $\begin{array}{c}\text { Canopy } \\
\text { density } \\
\text { (shoots / m) }\end{array}$ & $\begin{array}{l}\text { Canop } \\
\text { density ( } \\
\text { layors }\end{array}$ & \begin{tabular}{l|l} 
py \\
(leat \\
s)
\end{tabular} & $\begin{array}{l}\text { Exposed } \\
\text { bunches (S) }\end{array}$ \\
\hline & & & & For Gu & yot or Spurred C. & Cordon & & \\
\hline 0.250 & 12 & & low & 1.2 & 16 & $3-4$ & & 0 \\
\hline $250-500$ & 12 & & low & 1.2 & 16 & $3-4$ & & 0 \\
\hline $500-750$ & 8 & & gdium & 1.0 & 10 & $2 \cdot 3$ & & $100-0$ \\
\hline 750-1000 & 6 & & igh & 0.8 & 8 & 2 & & $100 \cdot 0$ \\
\hline 1000-1250 & 6 & & high & 0.8 & 8 & 2 & & 100 \\
\hline
\end{tabular}

Fig. 4. Imereti region card, management tables.

In conclusion, it is important to highlight that this new agrometeorological characterization of Georgia provided robust information. Based on this useful information, the handbook will provide guidelines for modern viticultural models, aimed to support and improve Georgian viticulture. The book will be soon published and freely distributed to grape-growers and technicians.

This work was done in the framework of the "Research Project for the Study of Georgian Grapes and Wine Culture" realized by the National Wine Agency of the Republic of Georgia since 2014 leaded by Giorgi Samanishvili Andro Aslanishvili and under responsibility of the Minister of Environmental Protection and Agriculture Levan Davitashvili.

The Köeppen - Geiger classification was kindly provided by climatologist Gizo Gogichaishvili with the support of GIS expert Giorgi Zedgenidze.

\section{References}

1. P. McGovern et al. Early Neolithic wine of Georgia in the South Caucasus. Proceedings of the National Academy of Sciences, 201714728 (2017)

2. D. Zohary, M. Hopf, Domestication of plants in the Old World, (3rd edn. Oxford University Press, p. 316, 2000)

3. N. Ketskhoveli, M. Ramishvili, D. Tabidze, Ampelography of georgia. (Georgian Academy of Science, Tbilisi (in Georgian and Russian), 1960)

4. D. Maghradze, L. Rustioni, A. Scienza, O. Failla, Journal of the American Pomological Society 66(2), 56-67 (2012)

5. D. Maghradze, L. Rustioni, J. Turok, A. Scienza, O. Failla, Journal of Grapevine Research (2012)
6. O. Failla, Vitis 54(Special Issue), 1-4 (2015)

7. L. Mariani, G. Cola, R. Bulgari, A. Ferrante, L. Martinetti, Science of the Total Environment, 562, 834-844 (2016)

8. J. Bai, P. Perron, J Appl Econ, 18 (1), 22 (2003)

9. L. Mariani, S. Parisi, G. Cola, O. Failla, Int J Biometeorol, 56, 1123-1134 (2012)

10. G.D. Mc Carthy, I.D: Haigh, J.J.M. Hirschi, J.P. Grsit, D.A. Smeed, Nature, 521, 508-510 (2015).

11. W. Köppen, R. Geiger, Handbuch der Klimatologie (Berlin, Verlag von Gebruder Borntraege, 1936)

12. R. Geiger, Klassifikation der Klimate nach W. Köppen. Landolt-Börnstein - Zahlenwerte und Funktionen aus Physik, Chemie, Astronomie, Geophysik und Technik, alte Serie. Springer, Berlin. 3, 603-607 (1954).

13. G. Cola, O. Failla, D. Maghradze, L. Megrelidze, L. Mariani, Int J Biometeorol (2016)

14. R.G. Allen, L.S. Pereira, D. Raes, M. Smith, Crop evapotranspiration - guidelines for computing crop water requirements. FAO Irrigation and drainage paper 56. Food and Agriculture Organization, Rome (1998) 